\title{
Zero Waste Management through Mindful Consumption for Sustainable Waste Solution
}

\author{
Chainarong Khaw-ngern ${ }^{1}$, Shayaniss Kono ${ }^{2}$, Nattakitt Udomphol ${ }^{3}$, Kannikar Khaw-ngern ${ }^{4}$ \\ ${ }^{1}$ Faculty of Humanities, Mahachulalongkornrajavidyalaya University, \\ ${ }^{2}$ Faculty of Social Sciences, Srinakharinwirot University, \\ ${ }^{3,4}$ Faculty of Buddhism, Mahachulalongkornrajavidyalaya University \\ 1 chainarong.kha@mcu.ac.th, ${ }^{2}$ shayaniss@g.swu.ac.th, ${ }^{3}$ nattakittu@gmail.com, ${ }^{4}$ kannikar.khaw@gmail.com
}

\begin{abstract}
Due to the population growth, economic expansion, and urbanization, waste becomes a critical problem of societies. Zero waste policies are a great and important way in which local businesses take an interest to preserve our environment. Going zero-waste, however, is a hard and intense process because there are many challenges and hindrances along the path. This article provides an overview of the guiding principles to solid waste management and to look at zero waste management in Japan, Singapore, and Thailand. It also suggests mindful consumption as tool for zero waste management towards sustainability. Documentary study and literature review were used for data collection. The result shows that zero waste management needs to be developed step-by-step and it needs involvement of all stakeholders. It can bring economic and environmental benefits to the countries, but it leads to more financial cost of implementation and operation. Mindful consumption, based on Buddhism principle of right mindfulness, is considered a helpful and practical way for everyone to help their communities reduce waste through moderate consumption. With mindfulness, individuals care not only for their own wellbeing, but for others, communities, and environment. They will participate in source separation, reuse, and recycling programs as they realize that conserving environment and reducing the use of natural resource over the life cycle of the service and products can lead their lives more sustainable. The right understanding in the cause and effect of waste can lead people to engage in waste reduction, reuse, and recycling and move towards sustainable waste solution.
\end{abstract}

Keywords

Mindfulness, Mindful Consumption, Zero Waste Management, Sustainable Waste Solution

Article Received: 10 August 2020, Revised: 25 October 2020, Accepted: 18 November 2020

\section{Introduction}

Waste generation around the world is constantly increasing. In 2016, 2.01 billioin tonnes of solid waste was generated around the world which was equal to a footprint of 0.74 kilograms per person per day. By 2050, annual waste generation can increase by $70 \%$ due to rapid population growth and urbanization [1]. According to report from World Bank, many local administrations will probably spend the highest budget only for waste management. This budget can take up $20 \%$ of municipal budgets in low-income countries, on average. Research suggests that investment in sustainable waste management could bring benefits to the country because poor waste management can cause significant health problems and environmental impacts. And tackling to these problems will cost many times higher than the cost of developing and operating proper waste management system. Since 2000, the World Bank has committed over $\$ 4.7$ billion to more than 340 solid waste management programs around the globe [2].

In Thailand the amount of municipal solid waste generated in 2018 was at 27.8 million tons, which is a $1.64 \%$ increase from 2017 due to expanding urban communities, and lifestyle changing from the shift of an agricultural to an urban society. Moreover, population growth, promoting tourism and higher consumption are also factors that cause higher amounts of solid waste in various areas [3]. The improvement of waste management resulted from government policy concerning Zero Waste Society, which is based on the 3R (Reduce, Reuse, Recycle) approach - civil state focuses on waste management at the source by the collaboration of both public and private sectors. There are still many problems and obstacles that we should consider, leading to the correction and improvement of waste management in various areas nationwide to make it efficient with value for money. The most efficient waste management includes the ability to reduce the impact that will cause injury to the public and damage to environment of the country concretely and sustainably.

Recycling innovation, the process of converting rubbish into new materials, is the best method for managing waste in zero waste concept; while incineration, the process of controlled combustion used to turn waste into energy, is considered far more favorable than landfill sites and illegal dumping. Zero Waste approach is a constructive way to conserve resources as a goal towards environmental and social justice and regeneration, equity and respect for nature. To achieve Zero Waste management, people in communities can also take part in the zero-waste process in reducing waste. With mindful consumption, they could offer a great help in minimizing waste at source. Mindful consumption, based on the Noble Eightfold Path of the Lord of Buddha, is a very clear, effective, and simple path of living, not just for personal benefit, but for whole species.

\section{Guiding Principles To Solid Waste Management Roadmap}

Waste collection and disposal have been operated since the historical time with its emphasis on protecting the health of local people and to improve the beautiful appearance of countries. The city growth and industrialization in 19th 
century led to more waste problems because it included a lot of non-perishable waste. In 20th century, waste amount was getting bigger and the problem became more complicated. There were more concerns and attention to environmental protection. Therefore, waste was viewed as a resource for material and energy recovery. Many developed countries gradually moved from deposal to prevention, recycling, and recovery. 28 member-states of the EU including Japan are the leaders in the development and application of environmental policies in the waste sector. Other countries are studying and replicating their examples. The 'sound material-cycle society' policy principles and the 'waste hierarchy' policy adopted by Japan and EU respectively are based on the same foundation of fewer natural resource consumption and more waste prevention, reuse, recycling, and recovery [4]. (Figure 1)

\begin{tabular}{cc} 
PREVENTION & PRODUCT (NON-WASTE) \\
\hline PREPARING FOR RE-USE & WASTE \\
RECYCLING & $\begin{array}{c}\text { Disposal in landfills implies } \\
\text { loss of the economic value } \\
\text { of waste. Moving up in the } \\
\text { waste hierarchy implies re-in- } \\
\text { troduction of resources into the } \\
\text { economy. }\end{array}$
\end{tabular}

Figure 1. Waste Management Hierarchy [5]

Although these policies for waste management can bring economic and environmental benefits to the countries, they lead to more financial cost. According to the World Bank's What a Waste report, the financial cost of recycling and incineration is exceeding USD 100 per ton. Even in the EU which follows the principles of "polluter pays", the households pay for waste service at average USD 260-350 per year. And in Japan, the cost of waste system is about USD. 500/ton which is financed by property taxes, subsidies, and waste fees. Moreover, low- and middleincome countries that have duplicated such principles confirm that they are not profit-generating activities. It also requires staff capacity, sufficient financing, environmental legal enforcement, and public environmental awareness for successful implementation of the waste hierarchy.

Therefore, the waste management roadmap has been established from analysis of the experience of Japan, the EU, and other countries including Azerbaijan, Belarus, Bulgaria, and Romania. Azerbaijan and Belarus have followed waste management approaches similar to those of the EU according to their strategy and planning documents. The roadmap is the extraction of the accumulated experiences taken from their different implementation and learned lessons with intention to make it practical for policy makers in low- and middle-income countries. Special attention is paid to the "building blocks" of a wellfunctioning waste management system, such as reliable data, legislation, institutional frameworks, financing, public communication and participation, management capacity, and operations [6]. As these elements are closely integrated, changes to any one of them results in changes to the others. It is therefore essential that intended sector reforms and changes are assessed holistically, and to the extent possible, with the involvement of all stakeholders. Key considerations and guiding principles to solid waste management roadmap are: [7]

1. Waste management system should be developed in a gradual approach which introduces step-by-step changes, and it should allow the sector to improve and grow naturally without interventions from outside.

2. The primary objective of the waste management system is to establish professional collection and disposal services for the country with full collection coverage in urban areas, substantial or full coverage in rural areas, and proper environmental practices at disposal sites.

3. Landfilling of waste can be an option only if it is a wellestablished and environmentally friendly when financial circumstances do not allow for costlier alternatives.

4. Once the countries can provide full collection coverage and environmentally disposal practices, they should consider waste separation and recycling as the next step. Moving up the 'waste hierarchy' for waste re-use, recycling, and recovery should be done only when they have sufficient resources for financing the increased costs that come with such improvements.

5. Recycling of household segregated waste is almost never a profitable activity. Compared to recovering recyclables from households, recovering recyclables from the commercial, institutional and industrial sector are easier to operate and less costly. In order to reduce financial burden of material recovery for public sector, governments should place the burden on the producers and importers.

6. Introducing Extended Producer Responsibility (EPR) to capture recyclables such as packaging waste, electric/electronic waste, end-of-life vehicles, and batteries is an effective instrument meeting the principle of 'polluter pays'. It takes time to develop comprehensive schemes in cooperation with key parties such as manufacturers of consumer products and packaging materials.

7. More advanced technologies for waste management such as mechanical and biological treatment (MBT) and waste to energy (WtE) can increase more financial cost, thus they should be considered only when a society is ready to pay the higher cost for waste service; is technically feasible; and sufficient technical capacity exists.

8. Sufficient financing is essential for running waste management system effectively. However, subsidies are not recommended because it may distort market conditions of the waste management.

9. Private sector may get involvement only if there is sufficient and reliable financing available to the sector, and if the public sector can provide meticulous contract enforcement and supervision of private activities.

10. There should be appropriate legislation for controlling waste management system at national, regional, and local levels, and local authorities should be responsible for actual service delivery and implementation. This requires adequate staffing capacity at all levels.

According to report from World Bank, waste management can be the single highest budget item for many local administrations. In low-income countries, it comprises $20 \%$ of municipal budgets, on average [8]. However, it is worth for investing in sustainable waste management system because the country will have to spend much higher cost on 
addressing health and environmental problems than the cost of developing and simple, adequate waste management systems.

In 2014, total municipal waste produced in Japan was the approximately 42 million tons. The most common methods for the treatment were incineration and recycling which about $80 \%$ is treated by incineration and about $19 \%$ is recycled, and only $1 \%$ is landfilled. The municipal solid waste management (MSWM) flow in Japan for financial year 2014 is shown in figure 2. The rates of intermediate treatment methods other than incineration consists of large article treatment $(30.7 \%)$, composting $(3.0 \%)$, feedstock making $(0.1 \%)$, anaerobic digestion $(1.0 \%)$, waste-to-fuels processing $(11.6 \%)$, and others $(53.5 \%)$ [9].

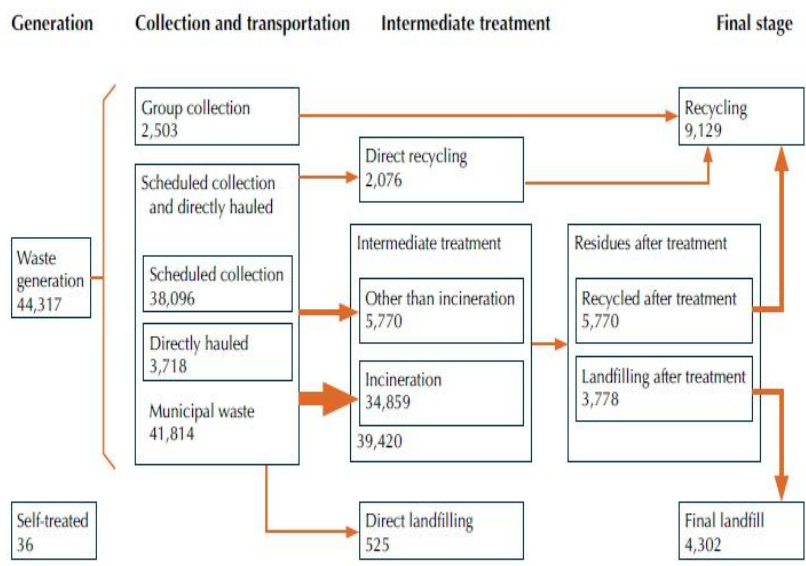

Figure 2. Flowchart of MSWM treatment in Japan in FY2014 [10]

When waste crises arise, it is generally the case that only two waste management options are proposed: bury or burn. But both landfills and incinerators require huge financial investments and offer a payoff that includes wasting and polluting. Zero waste invests in resource conservation; its payoff is the prevention of future waste crises, among other worthwhile benefits (e.g., more jobs, less pollution). There is no single correct way to start a zero waste program, because it must be tailored to the unique locality where it will be implemented. Thus, zero waste will not happen overnight. Especially when there is no system of materials separation already in place, being patient and consistent in starting a zero waste plan is extremely important. In many places, new government administrations bring new programs for waste management that are not sustained over time. The 'Basic Act on stablishing a Sound Material-Cycle Society' establishes a vision for a sound material-cycle society that consumes fewer natural resources and causes less environmental impact. At the same time, the law specifies the order of priority in the management of recyclable resources along the waste hierarchy as (1) reduction of generation, (2) reuse, (3) recycling, (4) thermal recovery, and (5) appropriate disposal [11].

Singapore has shown how economic growth, environmental protection and social inclusion can go hand in hand to build a sustainable Singapore. But it is facing new challenges because its limited resources are increasingly strained by rising consumption from population growth and rapid urbanization, which contributes to more waste. It is still a challenge for Singapore to promote economic resilience to ensure the future Singapore economy by overcoming carbon and resource constraints. The Masterplan will lay out Singapore's strategies to build the resilience and want to move towards a circular one that reuses resources endlessly. (as figure 3 below) To achieve these targets through sustainable production and consumption and transforming trash into treasure, sustainable consumption needs a change in mindsets and behaviors. Singapore scheduled 2019 as the Year "Towards Zero Waste" to raise a national awareness of the environment protection. The Government will support industry transformation and the upskilling of its workforce to create new economic opportunities for local companies, and good jobs for Singaporeans [12].

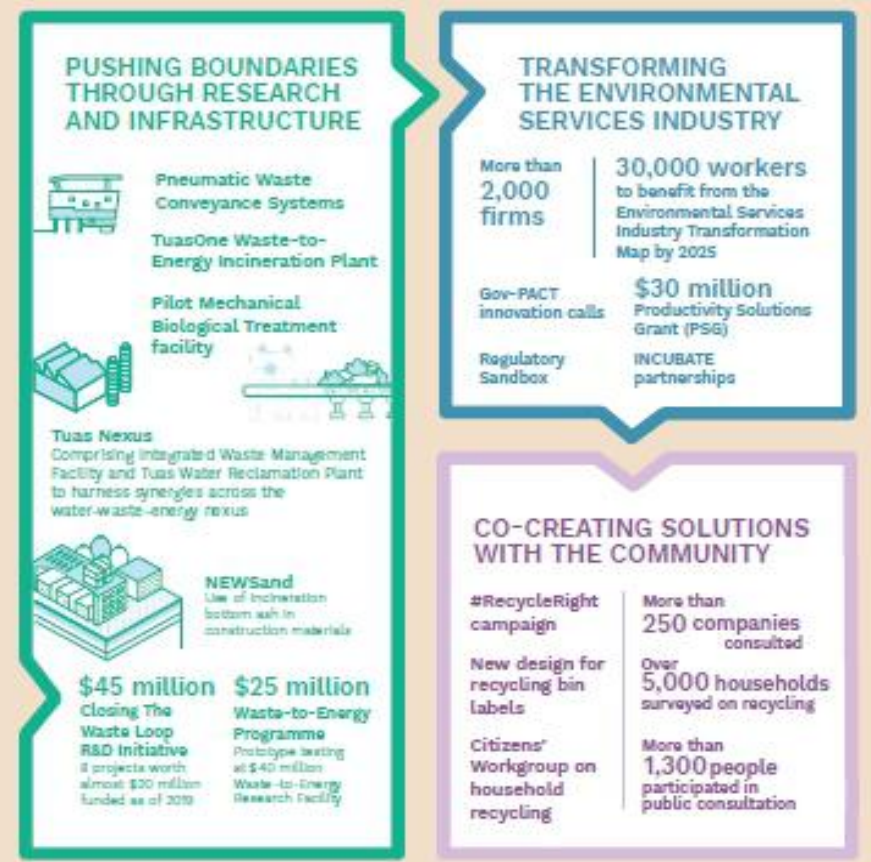

Figure 3. Singapore Zero Waste Masterplan [13] 
In Thailand, Master Plan for waste management 2016-2021 was approved by the Prayut government in May 2016. It includes a series of new waste management policies with the commitment to replace open dumping sites and improper waste treatments with sanitary landfills and incineration; and to rehabilitate many existing open dumping sites. Also, Pollution Control Department (PCD) under the Ministry of Natural Resources and Environment (MONRE) also provided guidelines for Local Administration Organizations (LAOs) to manage 77,000 tons of untreated MSW within the year 2019 [14]. To achieve this plan, however, there are several challenges ahead such as lack of financial and technical supports for local governments and inadequate staff for operation. It also requires national and local political commitment to work on specific national and local solutions, and it needs contribution of everyone in the society.

Thailand generates a large amount of municipal waste, at about 27 million tons each year year [15]. Municipal waste generation in Thailand is $1.05 \mathrm{~kg}$. per day as of 2016, which comes in fourth place among ASEAN countries after Singapore, Brunei and Malaysia [16]. Out of the 27 million tons, $76.23 \%$ is collected in collection areas, $17.65 \%$ is recycled, and $31.06 \%$ is properly treated, while $26.63 \%$ is improperly treated. Of the $31.06 \%$ of the properly treated MSW, $25.66 \%$ goes to landfills, $1.52 \%$ is incinerated, while only $1.82 \%$ is composted. The composition of MSW is mostly (1) Food/Organic waste 64\%, (2) Paper 8\%, (3) Plastic 17.6\% and (4) Metal 2\% [17].

To tackle the waste problems, Thai government, along with several private companies and organizations, aim to turn Thailand into a 'zero-waste society'. Besides policy, regulatory framework, programs, and plans for zero waste management, the Department of Environment Quality Promotion has issued a 'Mission Zero Waste' educational booklet for use in schools. It provides helpful suggestions for ways that youngsters can contribute to the zero waste by reducing, reusing and recycling their waste. The department has also introduced a 'Zero Waste Community' award for villages that are able to significantly reduce the amount of waste that they produce. The turnout is satisfactory; in 2017 over 700 villages entered the competition, which was won by two villages in Buriram Province in the country's northeast [18]. In order to reduce their waste, the villagers separated and recycled all their plastic, paper and glass, and turned their organic waste into fertilizer and organic insecticide instead of using chemicals on their farms.

It can be seen that one of significant contributions to zero waste management is the awareness and cooperation from households and people in communities because it can contribute to waste reduction and higher recycle rate as well as it can be a key factor of enhancing eco-friendly and sustainable productions in the business sectors. To raise the awareness and cooperation, there is a need to develop educational programs and a policy framework to promote the understanding and awareness of the local residents.

\section{Mindful Consumption For Sustainable Waste Management}

The increasing waste amount and problems nowadays primarily are caused by mindlessness, an automatic mental processing which leads us to make decisions and do things routinely and automatically [19]. Many of us are not aware that our daily actions are unsustainable and lead to environmental problems, such as dumping all trash into one bin, and throwing out unfinished food that accumulates on landfills and produces greenhouse gases. On the contrary, mindfulness leads us to more eco-friendly and sustainable actions. It extricates us from automatic thoughts and become more open to behavioral change [20].

Mindful consumption is a concept based on Buddhism's right mindfulness. Buddhism cannot avoid facing the problems of modernity, thus, it should reflect on how exponentially increasing consumption in modern world significantly violate human wellbeing and environmental sustainability. In modern world, people view consumption as a life process for satisfaction, for example, they feel happier living in a bigger house than in a smaller house, even it takes up a heavy mortgage [21]. Most Ven. P. A. Payutto [22] also draws attention to the teaching of the two kinds of wanting, tanhā and chanda, both of which have a fundamental role in consumption. Tanhā means desire for pleasurable objects and chanda means striving for wellbeing and need fulfillment. Tanhā could be called neverending want, while chanda is the aspiration for right and skillful. Consumption driven by tanhā can lead to more obtaining and excessive possession, while consumption driven by chanda brings satisfaction of life's basic needs, which contributes to well-being and forms a solid basis for the further development of human potentialities [23]. Besides, mindfulness help individuals recognize the impact of their consumption on others and the environment.

Individuals who make their consumption choices with mindfulness are able to respond their basic needs and bring a better quality of life. They care not only for their own wellbeing, but also for others, their community, and the environment. They will engage in waste prevention through their moderate consumption behavior. They also participate in source separation, reuse, and recycling programs as they realize that conserving environment and reducing the use of natural resource over the life cycle of the service and products can lead their lives more sustainable. (Figure 4) However, the way of living in our society is likely following the pattern of that individuals participate in conspicuous consumption. The younger generations also grow up in this spending and consuming environment which makes it harder for us to find our way out of it.

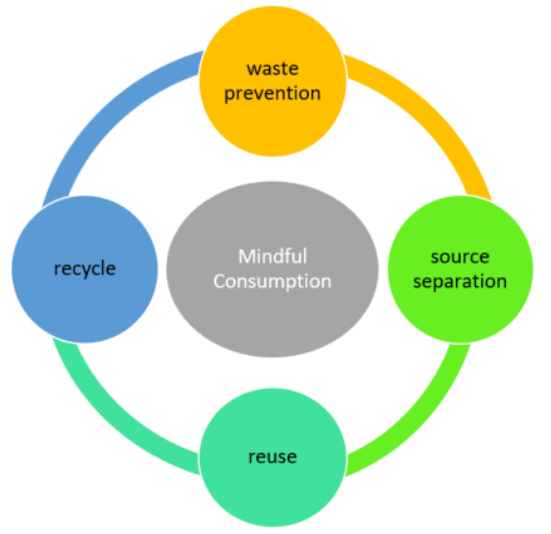

Figure 4. Zero Waste Management through Mindful Consumption for Sustainable Waste Solution 
Changing the consumption patterns following this approach is a challenge for today's society which is following capitalism. Industries are trying to encourage consumers to spend as much as possible on their products and services, such as those that manufacture products. Whether it is a food product or personal items, they are trying to produce the packages with beautiful colors and patterns and make it is easy to carry and for single use. That is only to add value to their products and attract the attention of consumers. But it is creating a lot of waste for the community. Therefore, consumers should stay mindful and consider what is necessary for their living, and what is superfluous or excessive and creates waste. One must be aware of how much is enough in the case of life's basic needs [24]. Right Mindfulness is one step in the Noble Eightfold Path, which is guided by Right Understanding and Right Thought. Applying mindfulness in consumption, an individual can eliminate simplistic thinking, the most serious problem of modernity, which leads them to spend just to respond to their requirements without thinking of the impacts to the environments. Practicing mindfulness in consumption, we can reduce a lot of waste, facilitate environmental preservation, and minimize the ultimate environmental impact of consumption which inline with zero waste management and leads to sustainability.

\section{Conclusion}

A zero-waste strategy needs to ensure everyone has access to tools to reduce, reuse and recycle waste where they live, work and play. This will let individuals to participate in saving the environment. It helps protect the health of communities by reducing pollution in the air, water and soil by keeping toxics and waste out of landfills and incinerators. With help of the waste hierarchy as a practical framework in the Action stage, consumers substitute previously consumed products with zero-waste alternatives and invest an intensive amount of time into grocery shopping, the preparation of food and personal care products, the reuse and recycling as well as the preparation of zero-waste utensils. Although it is nice to have had a Zero Waste road map or plan in place from the beginning, we should not trade the small victories, some defeats and failures, education, support and mentoring for a pre-structured plan. What we learned is that we must be able to adapt to the barriers and other challenges along the way.

Right mindfulness, one step in the Noble Eightfold Path of Buddhism, is guided by Right Understanding and Right Thought. Buddhism cannot avoid facing the problems of modernity, thus, it should reflect on how exponentially increasing consumption in modern world significantly violate human wellbeing and environmental sustainability. It can also influentially shape the framework of responsible consumption with recognition of self, social, and environmental wellbeing. As leading a life in accordance with the mindfulness, we can moderate our consumption and recognize how much is enough, thus we will minimize amount of waste at source, and we will contribute to reduce, reuse, and recycling in order to achieve the goal of zero waste. With the guiding principles to solid waste management and mindful consumption, we can ensure a sustainable and healthy environment for future generations. With care of self, social, and environmental wellbeing, individuals can play a significant role in contributing to zero waste scheme. They will take part in waste prevention through their moderate consumption behavior. They also participate in source separation, reuse, and recycling programs as they realize that conserving environment and reducing the use of natural resource over the life cycle of the service and products can lead their lives more sustainable. Such lifestyle is determined as a journey and constant improvement process, in which individuals must maintain their behavior change through their routines while undergoing a constant process of improvement in their actions. Mindfulness will disengage them from their over consuming routines and help them become more open to behavioral change. With progressive confidence in the lifestyle, individuals can transfer zero-waste efforts to more areas of their life and increasingly impacted their environment. It is merely that we need to recognize the truth of our power to create a better world for ourselves and future generations.

\section{References}

[1] Kaza, S. \& et al. (2018). What a waste 2.0: A global snapshot of solid waste management to 2050. Washington, DC: World Bank.

[2] World Bank. (2018). Global Waste to Grow by 70 Percent by 2050 Unless Urgent Action is Taken: World Bank Report. Retrieved 27 December 2020 from https://www.worldbank.Org/en/news/press -release/2018/09/20/global-waste-to-growby-70-percent-by-2050-unless-urgentaction-is-taken-world-bank-report

[3] Pollution Control Department. (2019). Booklet on Thailand State of Pollution 2018. Bangkok: S.Mongkon Press.

[4] World Bank Group. (2018). Municipal solid waste management: A roadmap for reform for policy makers. Tokyo: Tokyo Development Learning Center.

[5] MOE, History and Current State of Waste Management in Japan. (2014) Retrieved 29 December 2020 from https://www.env.go.jp/en/recycle/smcs/atta ch/hcswm.pdf

[6] "Zero Waste Masterplan SINGAPORE". Retrieved 30 December 2020 from https://www.towardszerowaste.gov.sg/ima ges/zero-waste-masterplan.pdf 
[7] Ministry of the Environment and Water Resources. (2018). Zero waste masterplan: Singapore. Singapore: Ministry of the Environment and Water Resources.

[8] Funatsu, T. (2019). Municipal Solid Waste Management in Thai Local Governments: The State of the problem and prospects for regional waste management, ERIA Collaborative/Support Research Report "Toward Regional Cooperation of Local Governments in ASEAN". IDE-JETRO. Retrieved 22 December 2020 from https://www.

ide.go.jp/library/English/Publish/Downloa d/Ec/pdf/201903_ch04.pdf

[9] "How Thailand is hurtling towards a massive waste disposal crisis". Retrieved 30 December 2020 from https://www.firstpost.com/world/thailandhurtling-towards-massive-waste-disposalcrisis-1690599.html

[10] United Nations Environment Program (UNEP) 2017 Waste Management in Asean Countries: Summary Report, Bangkok.

[11] Tourism Authority of Thailand (2018). Thailand Aims for Zero Waste. Retrieved 30 December 2020 from https://7greens.tourismthailand.org/greencontent/thailand-aims-for-zero-waste/

[12] Langer, E.J., \& Piper, A.I. (1987). The prevention of mindlessness. Journal of Personality and Social Psychology, 53(2), 280-287.

[13] Brown, K.W., \& Ryan, R.M. (2003). The benefits of being present: mindfulness and its role in psychological well-being. Journal of Personality and Social Psychology, 84(4), 822-848.

[14] Stanca, Luca \& Veenhoven, Ruut: Consumption and happiness. Retrieved 30 December $\quad 2020 \quad$ from https://link.springer.com/article/10.1007/s1 2232-015-0236-X

[15] Phra Brahmagunabhorn (P. A. Payutto). Buddhist Economics. Bangkok: Wat Nyanavesakavan, 2016.
[16] Gábor Kovács. (2019). “The Framework of Right Consumption" in Buddhist Approach to Responsible Consumption and Sustainable Development. Hanoi: Hong Duc Publishing House. 